\title{
Practical considerations for pancreas ultrasound elastography in pediatric patients before application of normal reference values
}

\author{
María M. Rojas-Rojas ${ }^{1}$ (D) Sergio Valencia ${ }^{1} \cdot$ Gustavo A. Triana ${ }^{1}$ \\ Received: 30 December 2020 / Revised: 30 December 2020 / Accepted: 27 January 2021 / Published online: 19 February 2021 \\ (C) The Author(s), under exclusive licence to Springer-Verlag GmbH, DE part of Springer Nature 2021
}

Dear Editors,

We have read with great interest the article titled "Pancreas ultrasound two-dimensional shear wave elastography in healthy children" by Qiu et al. [1] published in the November issue. In this study, the authors measured pancreas shear-wave speed, providing reference values for normal against which pancreatic disease states might be compared [1]. Therefore, we consider that this work is a significant contribution to the evaluation of pancreas disorders and have some questions for the authors about the study.

Guidelines for performing US elastography for the assessment of liver diseases are available; however, no consensus has been published regarding pancreas studies. The US consensus statement on liver elastography recommends that 10 measurements be obtained in point shear-wave elastography (pSWE) and that the final result be expressed as the median together with the interquartile range to mean ratio (IQR/M). Fewer than 10 measurements can be obtained (at least five); however, the IQR/M should be within the recommended range [2]. In two-dimensional SWE, five measurements are adequate if the manufacturer provides a quality assessment. If a quality assessment is not available, 10 measurements are recommended. So we wonder whether the authors considered that a greater number of measurements $(>5)$ could make the result more accurate in US elastography of the pancreas.

Also, in this analysis, good-quality measurements were obtained in the pancreas body or tail and we would like to know whether shear-wave speed values differed according to the region tested and whether this could affect overall value of speed.

María M. Rojas-Rojas

mm.rojas1828@uniandes.edu.co

1 Radiology Department, Hospital Universitario Fundación Santa Fe de Bogotá, Carrera 7 \#117-15, Bogotá, Colombia
Mean pancreas shear-wave speed for the population was $1.31 \pm 0.14 \mathrm{~m} / \mathrm{s}$ and median pancreas shear-wave speed was $1.31 \mathrm{~m} / \mathrm{s}$ (interquartile range [IQR]: 1.21-1.40). Given that SWE can measure the elasticity of the tissue in an organ as kilopascals $(\mathrm{kPa})$ or shear-wave velocity (meters per second, $\mathrm{m} / \mathrm{s}$ ), do the authors recommend reporting the results as $\mathrm{m} / \mathrm{s}$, $\mathrm{kPa}$ or both?

Finally, fat deposition in the liver is thought to make the tissue softer so that stiffness reduces with progressive hepatic steatosis. However, pancreas elastography studies have not shown conclusive results about tissue stiffness measuraments and fatty pancreatic disease [3]. We consider that the findings in this investigation could be used as a reference for further studies, but we are interested to hear about the authors' opinion regarding this subject in pediatric patients.

\section{Declarations}

Conflicts of interest None

\section{References}

1. Qiu L, Trout AT, Bennett PS, Dillman JR (2020) Pancreas ultrasound two-dimensional shear wave elastography in healthy children. Pediatr Radiol. https://doi.org/10.1007/s00247-020-04863-2

2. Barr RG, Wilson SR, Rubens D et al (2020) Update to the Society of Radiologists in Ultrasound liver elastography consensus statement. Radiology 296:263-274

3. Sakai NS, Taylor SA, Chouhan MD (2018) Obesity, metabolic disease and the pancreas - quantitative imaging of pancreatic fat. Br J Radiol 91:20180267

Publisher's note Springer Nature remains neutral with regard to jurisdictional claims in published maps and institutional affiliations. 